Original Research

\title{
Challenges of Online Education among University Students, Saudi Arabia
}

\section{Lizy Sonia Benjamin'1, B. Joshua Steve Abishek², Yulis Setiya Dewi ${ }^{3}$, Priya Sivaram ${ }^{4}$, and Yoyok Bekti Prasetyo ${ }^{5}$}

${ }^{1}$ Department of Medical-Surgical Nursing, King Khalid University, Abha, Kingdom of Saudi Arabia

2Department of Bioinformatics, SASTRA University, Thanjavur, India

${ }^{3}$ Faculty of Nursing, Universitas Airlangga, Surabaya, Indonesia

${ }^{4}$ Apollo College of Nursing, Chennai, India

${ }^{5}$ Faculty of Health Sciences, University of Muhammadiyah Malang, Indonesia

\begin{abstract}
Introduction: Online education during COVID 19 pandemic is witnessing significant growth, particularly in higher education. The aim of the study will explore the challenges that are being encountered related to online education for nursing students.
\end{abstract}

Methods: A correlational study using cross-sectional approach was adopted among 150 participants selected through convenient sampling technique. Data was collected through electronic survey from undergraduate students participated voluntarily studying in College of Nursing, King Khalid University, Abha, Saudi Arabia. The survey forms (Rating Scales on satisfaction and barriers of online education) were used to collect the data. Descriptive and inferential statistics were used to analyze the data by using SPSS version 24.0.

Results: The results revealed nearly $92 \%$ of participants were highly satisfied with online education. The mean scores and SD related to satisfaction of online education was $(37.50+8.50)$. The global perceived barriers mean scores and SD were $(35.19+11.19)$ which indicates that they were able to quickly adopt new strategies by overcoming the limitations.

Conclusion: The researcher concludes with the fact that study findings support that, students had positive perception on benefits of online learning by overcoming the limitations. In conclusion, online teaching and learning can be effectively incorporated in future also using blended approach.

\section{ARTICLE HISTORY}

Received: July 05, 2021

Accepted: November 16, 2021

\section{KEYWORDS}

online education; e-learning; nursing; COVID 19 Pandemic; university students

\section{CONTACT}

Yulis Setiya Dewi $\triangle$ yulis.sd@fkp.unair.ac.id $\equiv$ Faculty of Nursing, Universitas Airlangga, Surabaya, Indonesia

Cite this as: Benjamin, L., S., Abishek, B., J., S., Dewi, Y., S., Sivaram, P., \& Prasetyo, Y., B. (2021). Challenges of Online Education among University Students, Saudi Arabia. Jurnal Ners, 16(2). 188-192. doi: http://dx.doi.org/10.20473/in.v16i2.28037

\section{INTRODUCTION}

Digital transformation is not a novel phenomenon, and it has been accompanying higher education institutions for some years now (Leszczyński et al., 2018; Kopp, Gröblinger and Adams, 2019). Digital transformation of Higher Education institutions is a topical issue that involves several stakeholders of education must feel concerned about, abilities to apply ICT in every spheres of life, thus universities must be up to the task of preparing potential professional to be able to face challenges and provide solutions (Sandkuhl, K., \& Lehmann, 2017; Bond et al.,
2018), and this transformation has suggested the integration of sustainable management to be able to adjust to the modifications enforced as a result of novel technologies (Abad-Segura et al., 2020) and pandemic recently. Digital transformation in the context of higher education institutions can be regarded as the summation of all digital processes required to accomplish transformation process that gives higher education institutions the opportunities to positively apply digital technologies optimally (Kopp, Gröblinger and Adams, 2019). This process also consists of adequate strategic preparation, trust establishment, thinking in processes, amalgamation 
and reinforcement of all parties involved, separate, collaborative and organizational knowledge (Cameron and Green, 2019). $\quad$ A study to assess the challenges of online education among undergraduate University students, King Khalid University, Saudi Arabia.

COVID-19 pandemic has disrupted face-to-face teaching in University students globally. The global impact of the COVID-19 pandemic on education systems across the world has led to major and rapid changes in the provision of higher and medical education, with increasing delivery of the curriculum by online approaches. A recent synthesis of the global responses by universities to the COVID-19 pandemic noted that the majority of universities were using online learning, but with differences between countries in the rapidity and extent of the shift (Gaur et al., 2020).

This pandemic has forced global physical closure of businesses, sport activities and schools by pushing all institutions to migrate to online platforms. Online learning is the use of internet and some other important technologies to develop materials for educational purposes, instructional delivery and management of program (Fry, 2001). There are two types of online learning, namely asynchronous and synchronous online learning, are majorly compared but for online learning to be effective and efficient, instructors, organizations and institutions must have comprehensive understanding of the benefits and limitations (Hrastinski, 2008).

Designing effective online learning requires careful consideration of many inter-related factors. The factors include the previous experience and preferences of students in using online learning, the experience of the educators in the use of online learning, the available technology, the learning content and the curriculum, the instructional approach to pro-vide activities that enhance learning and the local context, such as the culture and available infrastructure resources (Zaharias and Poylymenakou, 2009). All of these factors are unique to a specific local context and optimization of online learning requires a close alignment between the different factors within each context.

The use of remote learning as an emergency measure has affected students, faculty, support staff, and administrators. The aim of this narrative review paper is to examine the challenges and opportunities faced by medical schools in implementing remote learning for basic science teaching in response to the COVID-19 crisis.

In a study conducted by (Sean, Block and Judge, 2014) regarding certified adapted physical educators' (CAPEs) advantages and disadvantages of online education. One-hundred and six CAPEs representing 29 states completed the survey in US. The age range was 22 to 67 years $(M=42), 72 \%$ of respondents were female, and average years of experience ranged from 1 to 38 years $(M=12.9)$. Nearly $86 \%$ reported to be satisfied with the experience.
The perceived barriers of online education were studied among 211 undergraduate students enrolled in Fundamental English course. Results indicated that the levels of needs and barriers of online learners in general were moderate. There were no statistically significant differences at 0.05 level found in barriers and needs of online learners as classified by gender, computer ownership, and computer aptitude. There was a negative relationship between computer

Table 1. Frequency \& Distribution of Demographic Variables of Participants Related to Challenges of Online Education (N=150)

\begin{tabular}{|c|c|c|}
\hline Baseline Characteristics & $\mathbf{n}$ & $\%$ \\
\hline \multicolumn{3}{|l|}{ Level } \\
\hline 3 & 32 & 21.3 \\
\hline 4 & 19 & 12.6 \\
\hline 5 & 18 & 12 \\
\hline 6 & 19 & 12.6 \\
\hline 7 & 28 & 18.6 \\
\hline 8 & 34 & 22.6 \\
\hline \multicolumn{3}{|l|}{ Age in years } \\
\hline $17-20$ & 113 & 75.3 \\
\hline $21-30$ & 19 & 12.6 \\
\hline Above 30 & 18 & 12 \\
\hline \multicolumn{3}{|l|}{ Gender } \\
\hline Female & 100 & 100 \\
\hline \multicolumn{3}{|l|}{ Marital status } \\
\hline Single & 141 & 94 \\
\hline Married & 9 & 6 \\
\hline \multicolumn{3}{|l|}{ Area of residence } \\
\hline Urban & 108 & 72 \\
\hline Rural & 42 & 28 \\
\hline \multicolumn{3}{|l|}{ Previous Online Education } \\
\hline No online experience & 101 & 74.3 \\
\hline Taken online courses & 49 & 25.7 \\
\hline \multicolumn{3}{|l|}{ Most commonly used online tool } \\
\hline Blackboard collaborator & 109 & 90.8 \\
\hline Zoom & 41 & 9.2 \\
\hline \multicolumn{3}{|l|}{ Preference of lectures } \\
\hline Live & 42 & 22.6 \\
\hline Recorded & 60 & 13 \\
\hline Live and recorded & 48 & 64.4 \\
\hline
\end{tabular}

Table 2. Mean and SD of Satisfaction Scores of Online Courses among the Students $(\mathrm{N}=150)$

\begin{tabular}{lcccc}
\hline \multicolumn{1}{c}{ Score } & $\begin{array}{c}\text { Obtainable } \\
\text { Score }\end{array}$ & Mean & SD & Level \\
\hline $\begin{array}{l}\text { Satisfaction } \\
\text { score }\end{array}$ & $10-50$ & 37.60 & 8.50 & $\begin{array}{c}\text { Highly } \\
\text { satisfied }\end{array}$ \\
\hline
\end{tabular}

Table 3. Mean and SD of Perceived Barriers of Online Courses among the Students (N=150)

\begin{tabular}{lccc}
\hline \multicolumn{1}{c}{ Barriers } & $\begin{array}{c}\text { Obtainable } \\
\text { Score }\end{array}$ & Mean & SD \\
\hline Teaching and learning & $5-25$ & 14.55 & 4.52 \\
Communication & $1-5$ & 2.27 & 1.14 \\
Use of technology & $1-5$ & 2.27 & 1.13 \\
Internet & $2-10$ & 5.36 & 2.16 \\
Physical & $4-20$ & 10.43 & 4.33 \\
Global Score & $13-65$ & 35.19 & 11.19 \\
\hline
\end{tabular}


aptitude and barriers of online learners at 0.01 level (Srichanyachon, 2014).

The pandemic has posed several challenges to premedical education (e.g., suspension of face-to-face teaching, lack of cadaveric dissections, and practical/laboratory sessions) but has provided many opportunities as well, such as the incorporation of online learning in the curriculum and upskilling and reskilling in new technologies. To date, many medical schools have successfully transitioned their educational environment to emergency remote teaching and assessments. During COVID-19 crisis, the preclinical phase of medical curricula has successfully introduced the novel culture of "online home learning" using technology-oriented innovations, which may extend to post-COVID era to maintain teaching and learning in medical education. However, the lack of hands-on training in the preclinical years may have serious implications on the training of the current cohort of students, and they may struggle later in the clinical years. The use of emergent technology (e.g., artificial intelligence for adaptive learning, virtual simulation, and telehealth) for education is most likely to be indispensable components of the transformative change and postCOVID medical education.

The article includes an exploration of the satisfaction, methods of evaluation and perceived barriers related to online education among students studying in college of Nursing, Saudi Arabia.

\section{MATERIALS AND METHODS}

A correlational study using cross-sectional approach was used to fulfill the objectives of the study. The total population of the nursing students at King Khalid University is 300 . The study adopted convenient sampling technique conducted among 150 undergraduate students studying B.Sc Nursing in College of Nursing, King Khalid University, Abha, Saudi Arabia. Female students above 17 years of age, who showed willingness to participate were only selected for the study.

Data was collected using tools such as baseline profile of participants and rating scale to assess the challenges of online education. The following tools were used for data collection. 1)Proforma to collect Baseline Variables of the students. It was used to collect information on background characteristics such as gender, age, experience, and characteristics related to computer skills and online teaching \& learning. 2)Rating Scale on Perceived benefits, of online education among students. There are 20-items, 5-point Likert scale (5-Strongly agree, 4-Agree, 3- Not sure, 2-Disagree, 1-Strongly Disagree). The obtainable score was 20-100. Higher scores indicated positive perception and vice versa. 3)Rating Scale on Perceived barriers, of online education among students. There are 20-items, 5-point Likert scale (1Not a barrier, 2- Somewhat a barrier, 3-Not sure, 4Barrier, 5- Significant Barrier) under five sub components such as teaching-learning barriers (5 items), physical barriers (5 items), internet barriers (3 items), technology barriers (3 items) and communication barriers ( 4 barriers). The obtainable score was 20-100. Higher scores indicated more barriers and vice versa.

The study was conducted after obtaining clearance from Ethical committee, King Khalid University, Saudi Arabia approval number ECM\#2020-0807. Consent was obtained from all the participants, before the data collection. Confidentiality was maintained throughout the study. Data was collected from participants through electronic google forms. Descriptive and inferential statistics were used to analyze the data by using SPSS version 24.0.

\section{RESULTS}

A total of 150 students participated in the study. Table 1 illustrates baseline profile of the participants from College of Nursing, King Khalid University, Abha. The

Table 4. Association between Selected Variables and Satisfaction of Online Education (N=150)

\begin{tabular}{|c|c|c|c|c|c|}
\hline Variables & $\mathbf{N}$ & Mean & SD & $\begin{array}{l}\text { Test statistics } \\
\text { (ANOVA- F) }\end{array}$ & $\begin{array}{c}\mathbf{p} \\
\text { value }\end{array}$ \\
\hline $\begin{array}{l}\text { Gender } \\
\text { Female }\end{array}$ & 150 & 35.22 & 10.96 & 1.28 & $p>0.05$ \\
\hline $\begin{array}{l}\text { Marital status } \\
\text { Single }\end{array}$ & 141 & 35.21 & 11.0 & 0.199 & $p>0.05$ \\
\hline Married & 9 & 34.76 & 14.38 & & \\
\hline $\begin{array}{l}\text { Area of residence } \\
\text { Urban } \\
\text { Rural }\end{array}$ & $\begin{array}{c}168 \\
82\end{array}$ & $\begin{array}{l}35.03 \\
35.61\end{array}$ & $\begin{array}{l}10.67 \\
12.56\end{array}$ & 0.516 & $p>0.05$ \\
\hline $\begin{array}{l}\text { Previous Online Educati } \\
\text { No online experience } \\
\text { Taken online courses }\end{array}$ & $\begin{array}{c}108 \\
41\end{array}$ & $\begin{array}{l}34.84 \\
35.27 \\
\end{array}$ & $\begin{array}{l}11.98 \\
11.01 \\
\end{array}$ & 0.342 & $p>0.05$ \\
\hline
\end{tabular}

Table 5. Correlation between Age and Satisfaction \& Age and Barriers of Online Courses Students (N=150)

\begin{tabular}{lcc}
\hline Variables & r value & p value \\
\hline Age vs satisfaction & 0.039 & $0.375 \mathrm{NS}$ \\
Age vs barriers & -0.008 & $0.856 \mathrm{NS}$ \\
\hline
\end{tabular}




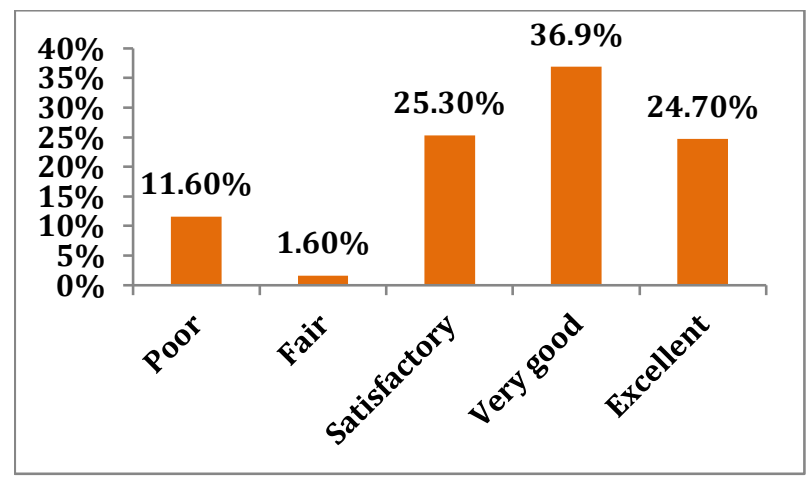

Figure 1. Percentage Distribution of Overall Rating on Online Courses Attended by The Students

respondents' opinions on whether online education was satisfactory or not and whether they would prefer online from traditional learning are vividly illustrated in the Tables and Figure 1.

The present study revealed that more than half of the study participants were between the age group of $17-20$ years $(53.3 \%)$ female students $(51.4 \%)$. Majority of the participants were unmarried (95.6\%) with their area of residence from city (73.4\%) had no online education previously. Majority of the participants utilized blackboard collaborator (90.8\%) preferred live and recorded lectures (64.4\%).

Table 2 denotes the satisfaction score of online education were highly satisfied with mean and SD $(37.50+8.50)$ and $92 \%$ were satisfied with online education.

The perceived barriers of online courses can be highlighted in Table 3. The global perceived mean scores and SD were $(35.19+11.19)$. Majority of the participants expressed teaching learning mean and SD $(4.55+4.52)$. Physical barriers $(43+4.33)$ internet barriers $(5.36+2.16)$ technology barriers $(2.27+1.14)$ and communication barriers $(2.27+1.13)$.

Figure 1 highlights majority of the participants rated overall online education to be very good (36.90\%) excellent $(24.70 \%)$ good $(25.30 \%)$ fair (1.60\%) and poor (11.60\%).

In Table 4 there were no significant association between selected demographic variables such as gender, marital status, area of residence, previous online experience, and satisfaction scores at $\mathrm{p}>0.05$ level of significance.

Table 5 indicates there is a weak negative correlation between age and satisfaction $(r=-0.03)$ which was not significant ( $p>0.05)$. Also, there is a weak negative correlation between age and barriers $(r=-0.008)$ which was not significant $(\mathrm{p}>0.05)$

\section{DISCUSSION}

This This study reports the challenges of online education among undergraduate students studying in College of Nursing, King Khalid University, Abha, Kingdom of Saudi Arabia. The study provides valuable information for administrators and faculty to consider as they wrestle with online delivery issues such as satisfaction, barriers and needs of online learners.
Majority of the participants $92 \%$ were satisfied with online education. This research supported previous finding that the students are satisfied with the university staff and faculty members who agreed on specific online platforms to use, grading system, assessment options, training workshops, online technical support, and more (Almusharraf and Khahro, 2020). The study results can be compared to similar study conducted among undergraduate students enrolled in Fundamental English course was moderately satisfied (Srichanyachon, 2014).

Majority of the participants expressed barriers as teaching learning. Some participants did voice concern about the lack of social interaction with teachers and students. There was also lack of personal relationship with teachers, lack of visibility with students. Physical barriers such as too much of eye strain, neck problems and typing problems were expressed by few participants. Another study also reveal similar finding that communication problem and physical barrier were another barrier for online learning (Baticulon et al., 2021). Communication barriers were expressed mean scores and SD $(2.27 \pm 1.13)$. Lack of communication skills were expressed by students in another study (Gupta et al., 2016). Similar findings are also reported in study conducted by (Srichanyachon, 2014) who reported that students found the barriers of online learning general in terms of communication barriers. Even though they are experiencing online education satisfaction, but they also encounter barriers with the new method of learning due to limited face to face direct communication.

Internet barriers such as frequent connectivity issues were expressed by students residing in remote areas, technology barriers such as navigation of portal, submitting assignments, increased load. This situation also similar to other study conducted by (Baticulon et al., 2021; Roslan and Halim, 2021) that technological constraint also experience by medical students which pertain to hardware, software, and internet connectivity. Another study also have similar finding that the use of technology as well as connectivity become detention in successfulness of online learning, along with the availability of internet devices (Efriana, 2021) It is true that, to successfully accomplish the task related to technology one must be skillful and confident in working with computers, which is further facilitated by accessibility and availability of the lap tops / desktops, practicing in day today life which is mandatory in the institutions of higher education. In the current study, moderate scores in perceived barriers may be due to the fact that, online education during covid-19 pandemic was first of its kind. Therefore, the students may be more anxious even though it was realized that, it was the only option which is available and feasible to continue learning to achieve the best outcome among the students. Many students were also more concerned about availability of the technology support for all especially those who are residing in villages and remote areas. At the same time, they also responded 
that, this in the only option which is available when traditional class room teaching method is not possible due to various circumstances, such as the current lockdown situation, facing major disaster, natural calamities etc.

In this research there was negative correlation between age and satisfaction with online courses, between age and barriers of online courses. Similar study also depicts there was a negative relationship between computer aptitude and barriers of online learners (Srichanyachon, 2014). This finding was not supported previous study (Baticulon et al., 2021) that students with older age found it difficult with self evaluation on online learning. Another study (Rabin et al., 2020) found that age provide contribution to barriers which leads to dissatisfaction in online learning. From this finding we can state that in some cases ages were not correlated with barriers and satisfaction where younger generation found excitement with new technology of learning where older generation may find it difficult to adapt with the new method.

\section{CONCLUSION}

Online technology education should take advantage of the perceived need to facilitate a wide variety of learner needs and capabilities. The coronavirus infection 2019 (COVID-19) pandemic is profoundly affecting emotional wellness. In conclusion, online education has found highly satisfied among undergraduate students. Faculty and institutions can take the results of this study into consideration for future development.

\section{REFERENCES}

Abad-Segura, E. et al. (2020) 'Sustainable management of digital transformation in higher education: Global research trends', Sustainability, 12(5), p. 2107. doi: 10.3390/su12052107.

Almusharraf, N. M. and Khahro, S. H. (2020) 'Students' Satisfaction with Online Learning Experiences during the COVID-19 Pandemic', International Journal of Emerging Technologies in Learning, 15(21), pp. 246-267. doi: 10.3991/ijet.v15i21.15647.

Baticulon, R. E. et al. (2021) 'Barriers to Online Learning in the Time of COVID-19: A National Survey of Medical Students in the Philippines', Medical Science Educator. Springer US, 31(2), pp. 615-626. doi: 10.1007/s40670-021-01231-z.

Bond, M. et al. (2018) 'Digital transformation in German higher education: Student and teacher perceptions and usage of digital media', International Journal of Educational Technology in Higher Education, 15(1), p. 48. doi: 10.1186/s41239-018-0130-1.

Cameron, E. and Green, M. (2019) Making sense of change management: A complete guide to the models, tools and techniques of organizational change. Kogan Page Publishers.
Efriana, L. (2021) 'Problems of Online Learning during Covid-19 Pandemic in EFL Classroom and the Solution', JELITA: Journal of English Language Teaching and Literature, 2(1), pp. 2721-1916.

Fry, K. (2001) 'E-learning markets and providers: some issues and prospects', Education + Training, 43(4/5), pp. 233-239. doi: 10.1108/EUM0000000005484.

Gaur, U. et al. (2020) 'Challenges and Opportunities of Preclinical Medical Education: COVID-19 Crisis and Beyond', SN Comprehensive Clinical Medicine. SN Comprehensive Clinical Medicine, 2(11), pp. 1992-1997. doi: 10.1007/s42399-020-00528-1.

Gupta, A. K. et al. (2016) 'an Online Survey of the Problems Being Faced By Students and Teachers in Higher Education With Special Reference To Jammu Region', MIER Journal of Educational Studies, 6(2), pp. 204-210. Available at: www.miercollege.in.

Hrastinski, S. (2008) 'Asynchronous and synchronous e-learning', Educause Quarterly, 31(4), pp. 51-55.

Kopp, M., Gröblinger, O. and Adams, S. (2019) 'Five common assumptions that prevent digital transformation at higher education institutions', in INTED2019, pp. 1448-1457. doi: 10.21125/inted.2019.

Leszczyński, P. et al. (2018) 'Multimedia and interactivity in distance learning of resuscitation guidelines: A randomised controlled trial', Interactive Learning Environments, 26(2), pp. 151-162. doi: 10.1080/10494820.2017.1337035.

Rabin, E. et al. (2020) 'What are the barriers to learners' satisfaction in MOOCs and what predicts them? The role of age, intention, self-regulation, self-efficacy and motivation', Australasian Journal of Educational Technology, 36(3), pp. 119-131. doi: 10.14742/AJET.5919.

Roslan, N. S. and Halim, A. S. (2021) 'Enablers and barriers to online learning among medical students during COVID-19 pandemic: An explanatory mixed-method study', Sustainability (Switzerland), 13(11). doi: 10.3390/su13116086.

Sandkuhl, K., \& Lehmann, H. (2017) 'Digital transformation in higher education - the role of enterprise architectures and portals', Digital Enterprise Computing.

Sean, H., Block, M. E. and Judge, J. P. (2014) 'Certified adapted physical educators' perceptions of advantages and disadvantages of online teacher development', Palaestra, 28(4), pp. 14-16.

Srichanyachon, N. (2014) 'The barriers and needs of online learners', Turkish Online Journal of Distance Education, 15(3), pp. 50-59. doi: 10.17718/tojde.08799.

Zaharias, P. and Poylymenakou, A. (2009) 'Developing a Usability Evaluation Method for e-Learning Applications: Beyond Functional Usability', International Journal of Human-Computer Interaction. Taylor \& Francis, 25(1), pp. 75-98. doi: $10.1080 / 10447310802546716$. 